\title{
Improved performance of non-thermal plasma reactor during decomposition of trichloroethylene: Optimization of the reactor geometry and introduction of catalytic electrode
}

\author{
M. Magureanu ${ }^{\mathrm{a}, *}$, N.B. Mandache ${ }^{\mathrm{a}}$, V.I. Parvulescu ${ }^{\mathrm{b}}$, Ch. Subrahmanyam ${ }^{\mathrm{c}}$, \\ A. Renken ${ }^{\mathrm{c}}$, L. Kiwi-Minsker ${ }^{\mathrm{c}}$ \\ ${ }^{a}$ National Institute for Lasers, Plasma and Radiation Physics, Str. Atomistilor 409, P.O. Box MG-34, 76900 Bucharest-Magurele, Romania \\ ${ }^{\mathrm{b}}$ University of Bucharest, Faculty of Chemistry, Department of Chemical Technology and Catalysis, Bd. Regina Elisabeta, \\ 4-12, 030016 Bucharest, Romania \\ ${ }^{\mathrm{c}}$ Ecole Polytechnique Fédérale de Lausanne (LGRC-EPFL), CH-1015 Lausanne, Switzerland \\ Received 30 December 2006; received in revised form 26 February 2007; accepted 27 February 2007 \\ Available online 3 March 2007
}

\begin{abstract}
The decomposition of trichloroethylene (TCE) by non-thermal plasma was investigated in a dielectric barrier discharge (DBD) reactor with a copper rod inner electrode and compared with a plasma-catalytic reactor. The particularity of the plasma-catalytic reactor is the inner electrode made of sintered metal fibers (SMF) coated by transition metal oxides. In order to optimize the geometry of the plasma reactor, the efficiency of TCE removal was compared for different discharge gap lengths in the range of 1-5 mm. Shorter gap lengths (1-3 mm) appear to be more advantageous with respect to TCE conversion. In this case TCE conversion varies between $67 \%$ and $100 \%$ for input energy densities in the range of 80-480 J/l, while for the $5 \mathrm{~mm}$ discharge gap the conversion was lower (53-97\%) for similar values of the input energy. As a result of TCE oxidation carbon monoxide and carbon dioxide were detected in the effluent gas. Their selectivity was rather low, in the range $14-24 \%$ for $\mathrm{CO}_{2}$ and $11-23 \%$ for CO, and was not influenced by the gap length. Several other chlorinated organic compounds were detected as reaction products.

When using MnOx/SMF catalysts as the inner electrode of the DBD reactor, the TCE conversion was significantly enhanced, reaching $\sim 95 \%$ at $150 \mathrm{~J} / 1$ input energy. The selectivity to $\mathrm{CO}_{2}$ showed a major increase as compared to the case without catalysts, reaching $58 \%$ for input energies above $550 \mathrm{~J} / 1$.
\end{abstract}

(C) 2007 Elsevier B.V. All rights reserved.

Keywords: Non-thermal plasma; Dielectric barrier discharge; Chlorinated volatile organic compounds; Trichloroethylene; Plasma-catalysis

\section{Introduction}

Air pollution by volatile organic compounds (VOC) is an issue of major concern due to both environmental and medical reasons. Non-thermal plasma generated in electrical discharges is attractive for VOC removal from contaminated air streams, since it can be operated at room temperature and atmospheric pressure, over a wide range of gas flow rates and concentrations [1-5]. The energy dissipated in the plasma is mostly used to accelerate the electrons and not spent on heating the entire gas stream, as in thermal or thermo-catalytic processes. The

\footnotetext{
* Corresponding author.

E-mail address: monimag@infim.ro (M. Magureanu).
}

energetic electrons in the plasma are highly efficient in producing radicals and oxidizing agents, which can react with the VOC molecules decomposing them.

Various types of electrical discharges have been investigated for the oxidation of chlorinated hydrocarbons: pulsed corona discharges [5-9], atmospheric pressure glow discharges [10], dielectric barrier discharges [8,9,11-16], dielectric packed-bed discharges $[3,4,8,12,15,17]$, surface discharges $[13,14,18]$. In a recent review of the physics and applications of dielectric barrier discharges (DBD) [2], Kogelschatz addresses also the treatment of VOC, mentioning as main advantages of DBDs their simplicity and scalability.

In this work trichloroethylene $\left(\mathrm{C}_{2} \mathrm{HCl}_{3}, \mathrm{TCE}\right)$ was chosen as a model VOC compound. The plasma was generated in a dielectric barrier discharge (DBD) operated in ac mode at 
$50 \mathrm{~Hz}$ frequency. In order to optimize the geometry of the discharge reactor, the effect of the discharge gap length on TCE conversion and on the selectivity to $\mathrm{CO}_{2}$ and $\mathrm{CO}$ was investigated. With increasing the discharge gap, the residence time of the gas in the plasma region increases, which was found to be beneficial for pollutants removal $[19,20]$. On the other hand, the electrical characteristics of the discharge also change with the gap length, which may also influence TCE oxidation.

Manganese oxides and manganese phosphates placed either inside the electrical discharge or downstream of the discharge reactor were found useful for the oxidation of benzene and toluene [12,19,21-23]. In these works it was suggested that Mnbased catalysts have the ability to decompose ozone, forming strong oxidizing species which react with the VOC molecules on the catalyst surface. When the catalysts are placed directly inside the discharge region other active species generated in the plasma can contribute as well to VOC decomposition. Therefore, the TCE decomposition was also performed in a novel plasma catalytic reactor described in Refs. [22-25]. The particularity of this novel reactor is the inner electrode made of sintered metal fibers (SMF) coated by transition metal oxides serving in the same time as electrode and as catalyst. In this work manganese oxide catalysts were deposited on SMF as a washcoat and tested for TCE decomposition.

\section{Experimental set-up}

The experimental set-up is illustrated in Fig. 1.

TCE vapor was introduced by passing a flow of air through a vessel containing liquid TCE. The concentration was varied by adding a flow of ambient air, and adjusting both flow rates by mass flow controllers (MFC-1 and -2). The total gas flow rate was $500 \mathrm{sccm}$. The plasma was generated in a DBD reactor kept at atmospheric pressure and ambient temperature. In some experiments manganese oxide catalysts were used; they were placed inside the plasma reactor, as described below. The effluent gas was analyzed by gas chromatography coupled with mass spectrometry (GC-MS) and also using an infrared gas analyzer for $\mathrm{CO}$ and $\mathrm{CO}_{2}$.

\subsection{Dielectric barrier discharge reactor}

A dielectric barrier discharge in coaxial configuration was used. The discharge reactor is shown in Fig. 2a, while Fig. 2b shows the structure of the catalytic inner electrode used in some experiments, which will be described later in more detail.

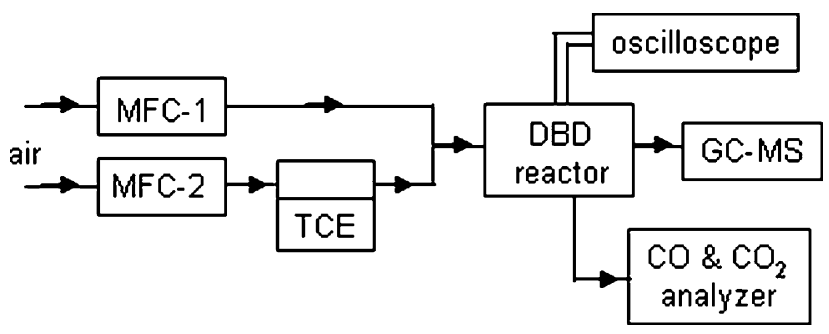

Fig. 1. Experimental set-up.

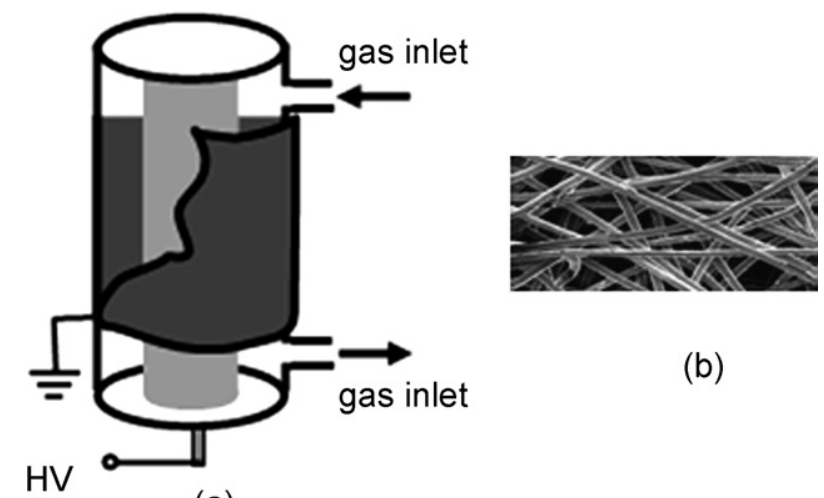

(a)

Fig. 2. (a) DBD reactor and (b) SMF catalytic electrode.

The DBD was generated in a cylindrical reactor made of quartz, with the outer diameter of $22 \mathrm{~mm}$ and $1.5 \mathrm{~mm}$ wall thickness. The inner electrode was a metallic rod placed on the axis of the reactor. Rods with diameters of 17, 13 and $9 \mathrm{~mm}$ were used, therefore the discharge gap was 1,3 and $5 \mathrm{~mm}$, respectively. The outer electrode was painted with silver paste on the outer surface of the quartz tube, and had a length of $10 \mathrm{~cm}$. The volume of the discharge was $5.7,15.1$ and $22 \mathrm{~cm}^{3}$ for the gap lengths of 1,3 and $5 \mathrm{~mm}$, respectively, and the corresponding residence times of the gas in the plasma zone were $0.7,1.8$ and $2.6 \mathrm{~s}$, respectively.

\subsection{Electrical measurements}

The electrical circuit is shown in Fig. 3.

A high voltage transformer with a transformation ratio $T_{\mathrm{R}}=300$ providing sinusoidal voltage at $50 \mathrm{~Hz}$ frequency was used. The voltage of $10-23 \mathrm{kV}$ amplitude was applied to the inner electrode, while the outer electrode was grounded. The discharge voltage was measured by a high voltage probe (Tektronix P6015A) with a resistance $R_{\mathrm{HV}_{\mathrm{p}}}=100 \mathrm{M} \Omega$ connected in parallel with the discharge. The current was determined from the voltage drop across a shunt resistor $\left(R_{\mathrm{C}}=3 \Omega\right)$ connected in series with the grounded electrode. The total charge was measured with a non-inductive capacitor $(C=1 \mu \mathrm{F})$, placed instead of the shunt resistor. The voltage, charge and current waveforms were monitored by a digital oscilloscope (Tektronix TDS 320). The average power dissipated in the discharge was measured by the Lissajous method [26].

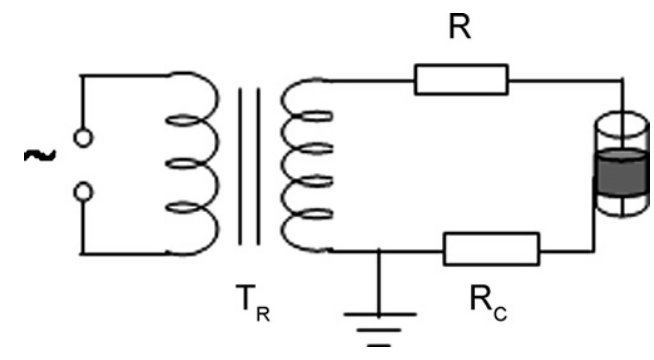

Fig. 3. Electrical circuit (transformation ratio: $T_{\mathrm{R}}=300, R=800 \mathrm{k} \Omega$ and $R_{\mathrm{C}}=3 \Omega$ ). 


\subsection{Catalysts preparation and characterization}

The catalysts preparation was described in detail in Ref. [22], therefore will be reminded here only shortly. Sintered metal fiber filters (SMF) made of stainless steel in the form of a uniform pore panel (thickness $0.29 \mathrm{~mm}$, porosity $80 \%, 675 \mathrm{~g} /$ $\mathrm{m}^{2}$ ) consisting of thin uniform metal fibers with diameters of $20 \mu \mathrm{m}$ were deposited with $3 \mathrm{wt} \%$ of $\mathrm{MnOx}$. For the deposition of $\mathrm{MnOx}$ the SMF was first oxidized at $600{ }^{\circ} \mathrm{C}$ for $3 \mathrm{~h}$, followed by impregnation with $\mathrm{Mn}$ nitrate aqueous solutions of desired concentration. After drying at room temperature and calcination at $500{ }^{\circ} \mathrm{C}$ in air for $5 \mathrm{~h}$ a MnOx catalytic film supported on SMF was obtained. The MnOx/SMF filters were shaped in cylindrical form and used as the inner electrode of the DBD reactor in the plasma-catalytic experiments.

The surface atomic concentrations were determined by XPS for the fresh catalysts as well as for the catalysts used in the oxidation reaction, using a SSX-100 Model 206 Surface Science Instrument spectrometer. Monochromatized $\mathrm{Al} \mathrm{K} \alpha$ radiation $(h v=1486.6 \mathrm{eV})$, obtained by bombarding the $\mathrm{Al}$ anode with an electron gun operating at a beam current of $12 \mathrm{~mA}$ and an accelerating voltage of $10 \mathrm{kV}$ was used. The peak positions were corrected for sample charging by setting the $\mathrm{C} 1 \mathrm{~s}$ binding energy at $284.8 \mathrm{eV}$. The relative surface concentrations of the elements were determined using the whole peak area of Fe 2p, Mn 2p, O 1s levels.

\subsection{Gas analysis}

The experiments were performed at atmospheric pressure and room temperature, in air with small amounts of TCE (150$200 \mathrm{ppm})$. The TCE concentration was determined by gas chromatography (GC), using a gas chromatograph (HewlettPackard 5890 series II) with flame ionization detector (FID) and a CP-Sil2 CB column (50 $\mathrm{m}$ length, $0.32 \mathrm{~mm}$ diameter). The presence of hydrocarbons in the effluent gas, as reaction products from the decomposition of the VOC was investigated by GC-MS (TRACE GC Ultra, column THERMO TR-5MS $30 \mathrm{~m} \times 0.25 \mathrm{~mm}$ ID, quadrupole MS TRACE DSQ). A gas analyzer (Ultramat 6) was coupled on line to monitor continuously the concentration of carbon dioxide and carbon monoxide resulting from the oxidation of TCE. The formation of $\mathrm{NO}$ and $\mathrm{NO}_{2}$ in the plasma was investigated by using a gas analyzer (Fischer Rosemount, type MLT 4T IR-IR-UV-IR).

The TCE conversion is calculated from:

$\operatorname{conv}(\%)=\left(1-\frac{[\mathrm{TCE}]_{\text {out }}}{[\mathrm{TCE}]_{\text {in }}}\right) \times 100$

where $[\mathrm{TCE}]_{\text {in }}$ is the concentration of TCE introduced in the reactor and $[\mathrm{TCE}]_{\text {out }}$ is the concentration of TCE in the effluent gas.

The selectivities to $\mathrm{CO}$ and $\mathrm{CO}_{2}$ are defined as

$S_{\mathrm{CO}_{x}}(\%)=\frac{\left[\mathrm{CO}_{x}\right]}{2[\mathrm{TCE}]_{\text {in }} \operatorname{conv}} \times 100$ where $\left[\mathrm{CO}_{x}\right], x=1,2$ is the concentration of $\mathrm{CO}$ and $\mathrm{CO}_{2}$, respectively, detected in the effluent gas as a result of TCE total oxidation.

\section{Results and discussion}

\subsection{Electrical characteristics of the discharge}

Voltage and current waveforms are shown in Fig. 4 for a peak voltage of $15 \mathrm{kV}$ and for the discharge gap of $1 \mathrm{~mm}$. They are typical for a filamentary ac DBD: several current peaks with amplitudes of tens to hundreds milliamperes and durations of ns to tens of ns appear on the voltage rise, both on the positive and on the negative alternance of the voltage waveform.

When the amplitude of the applied voltage $\left(V_{\text {peak }}\right)$ is low:

$V_{\text {peak }}<V_{\mathrm{b}} \frac{C_{\text {diel }}+C_{\text {gas }}}{C_{\text {diel }}}$

where $V_{\mathrm{b}}$ is the effective gas breakdown voltage, $C_{\text {diel }}$ the capacitance of the dielectric and $C_{\mathrm{gas}}$ is the capacitance of the gas, the discharge reactor is purely capacitive [27]. The voltage across the discharge gap ( $\left.V_{\text {gas }}\right)$ is not high enough to ignite a plasma. In this case the voltage and the charge are in

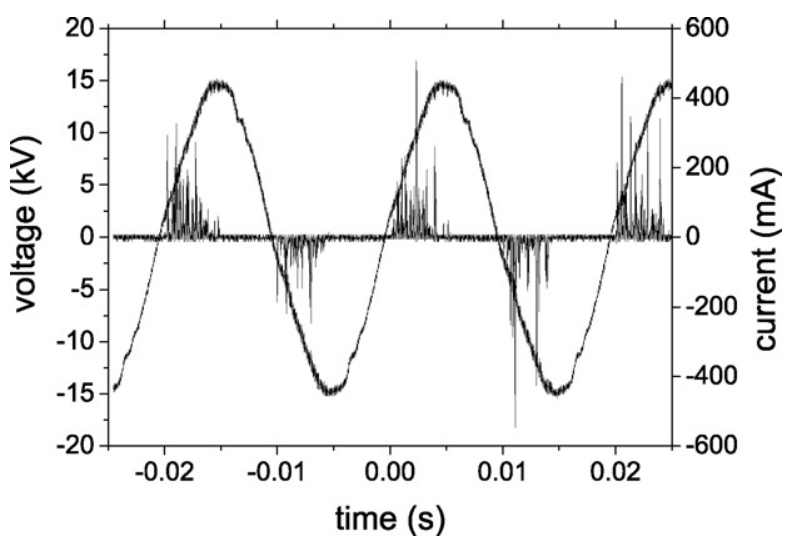

Fig. 4. Typical voltage and current waveforms (discharge gap: $3 \mathrm{~mm}$, amplitude of the applied voltage: $15 \mathrm{kV}$ ).

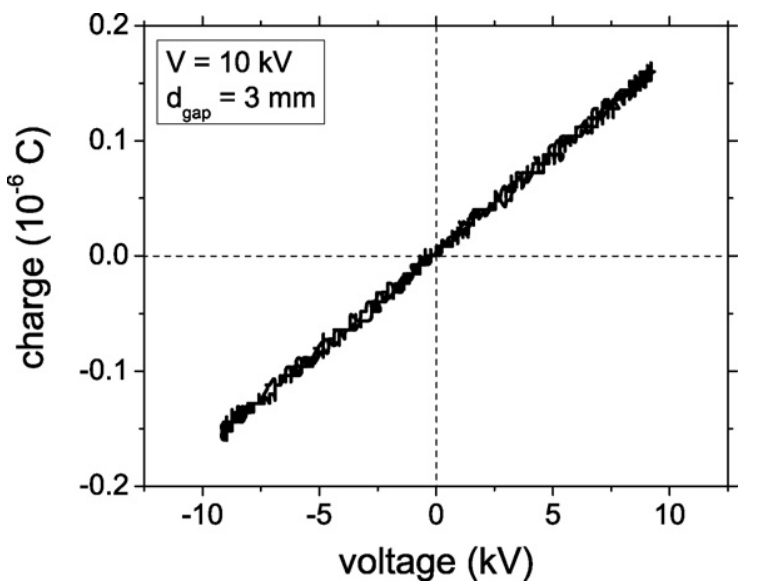

Fig. 5. Lissajous figure for a voltage lower than the ignition voltage (discharge gap length: $3 \mathrm{~mm}$, amplitude of the applied voltage: $10 \mathrm{kV}$ ). 


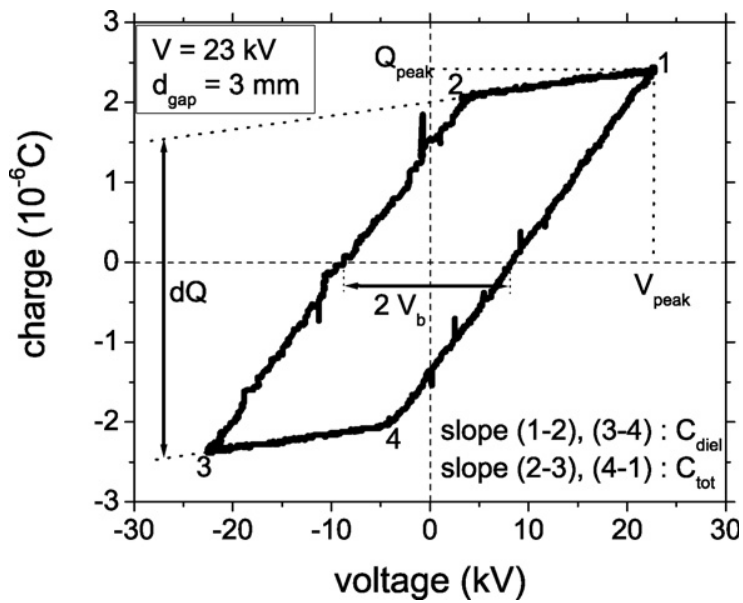

Fig. 6. Typical Lissajous figure for a dielectric barrier discharge (discharge gap length: $3 \mathrm{~mm}$, amplitude of the applied voltage: $23 \mathrm{kV}$ ).

phase and the Lissajous figure (the charge plotted against voltage) is a straight line which intercepts the origin, as shown in Fig. 5. The slope of this line is equal to the total capacitance $\left(C_{\text {tot }}\right)$ :

$C_{\mathrm{tot}}=\frac{C_{\mathrm{diel}} C_{\mathrm{gas}}}{C_{\mathrm{diel}}+C_{\mathrm{gas}}}$.

When the voltage is high enough to cause the breakdown of the gas, the charge is phase shifted with respect to the voltage due to resistive losses in the discharge. In this case the Lissajous figure becomes a parallelogram, as shown in Fig. 6 .

The lines (1-2) and (3-4) in Fig. 6 represent the capacitive transitions, and their slope is equal to the total capacitance of the discharge reactor $C_{\text {tot }}$. The lines (2-3) and (4-1) are the discharge transitions, and their slope is equal to $C_{\text {diel }}$. The Lissajous figure intercepts the voltage axis at values equal to $\pm V_{\mathrm{b}}$, therefore $V_{\mathrm{b}}$ can be measured directly from the chargevoltage plot. In Fig. $6 \mathrm{~d} Q$ is the total charge transferred by the microdischarges per half cycle. The area of the parallelogram is equal to the energy deposited in the discharge in a cycle [26].

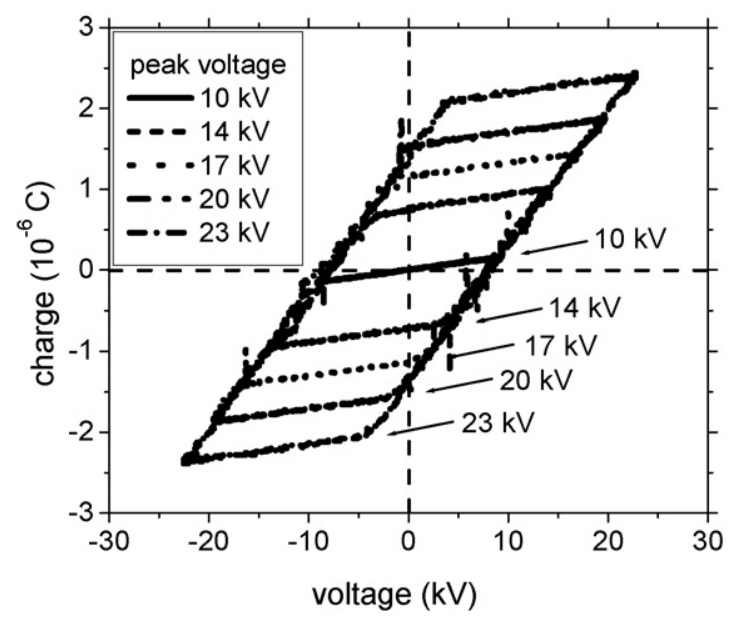

Fig. 7. Lissajous figures for the discharge gap of $3 \mathrm{~mm}$, for applied voltages with amplitudes in the range $10-23 \mathrm{kV}$.
The average power dissipated in the discharge can be calculated by multiplying this area with the frequency.

Fig. 7 shows the Lissajous figures for the discharge gap of $3 \mathrm{~mm}$, for applied voltages with amplitudes in the range 10$23 \mathrm{kV}$. The Lissajous figures for the three values of the discharge gap (1,3 and $5 \mathrm{~mm}$ ) are shown in Fig. 8, for an amplitude of the applied voltage of $23 \mathrm{kV}$.

At constant gap length, the energy per cycle, the average power and the total transferred charge increase with increasing voltage. When the gap length is increased the effective breakdown voltage also increases. This can be seen in Fig. 8: $V_{\mathrm{b}}$ is around $3.3 \mathrm{kV}$ for the $1 \mathrm{~mm}$ gap length, it increases to $8 \mathrm{kV}$ for the reactor with $3 \mathrm{~mm}$ gap and to $11.8 \mathrm{kV}$ for the $5 \mathrm{~mm}$ gap length. As expected, the total capacitance decreases with increasing the gap length. In the present measurements $C_{\text {tot }}$ is $40 \mathrm{pF}$ for the $1 \mathrm{~mm}$ gap length and decreases to 17 and $10 \mathrm{pF}$ for the gap lengths of 3 and $5 \mathrm{~mm}$, respectively.

Fig. 9 shows the average power as a function of the peak voltage, for the three gap lengths used.

The power increases almost linearly with voltage in all cases, but the increase is more pronounced for longer gap

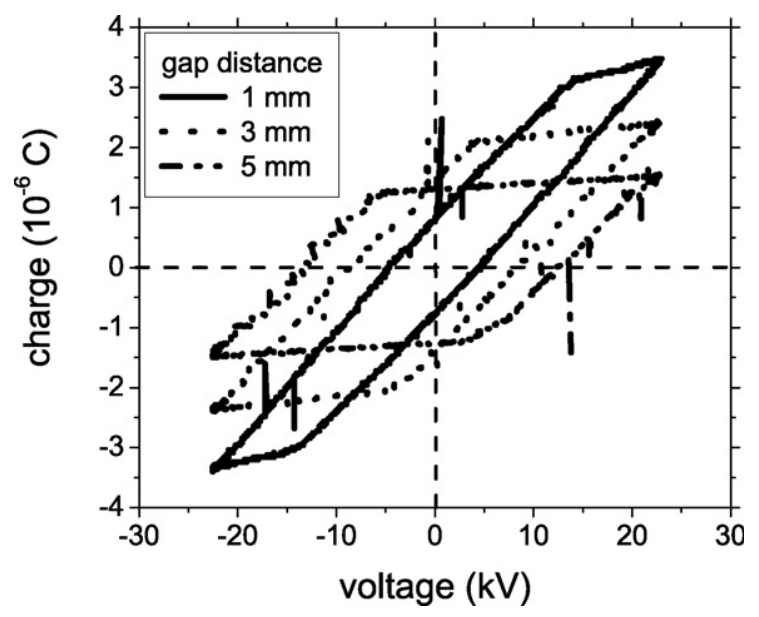

Fig. 8. Lissajous figures for discharge gap lengths of 1,3 and $5 \mathrm{~mm}$ and an amplitude of the applied voltage of $23 \mathrm{kV}$.

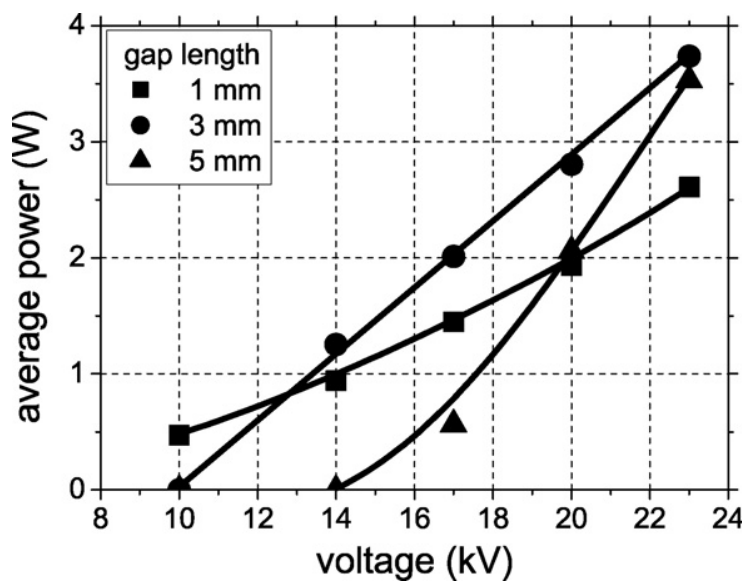

Fig. 9. Average power dissipated in the discharge as a function of the peak voltage, for discharge gap lengths of 1,3 and $5 \mathrm{~mm}$. 


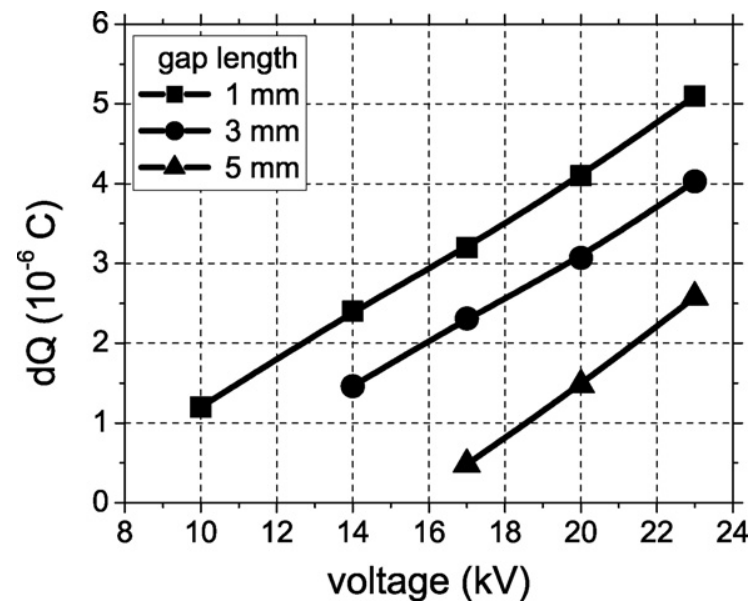

Fig. 10. Total charge transferred by the microdischarges per half cycle as a function of voltage, for discharge gap lengths of 1,3 and $5 \mathrm{~mm}$.

lengths. Over the range of applied voltages used in the present experiments the average power varies in the range $0.5-2.6 \mathrm{~W}$ for the $1 \mathrm{~mm}$ gap length, $0-3.7 \mathrm{~W}$ for the $3 \mathrm{~mm}$ gap length and $0-3.5 \mathrm{~W}$ for the $5 \mathrm{~mm}$ gap length. At these low power levels, no significant heating of the gas in the plasma region takes place.

The total charge transferred by the microdischarges per half cycle is shown in Fig. 10, for the three gap lengths used. The charge increases with increasing the applied voltage and with decreasing the gap length. At the maximum applied voltage used, the total charge is approximately $5 \mu \mathrm{C}$ for the shortest discharge gap and decreases to 4 and $1.5 \mu \mathrm{C}$ for the 3 and $5 \mathrm{~mm}$ gap length, respectively.

\subsection{TCE decomposition in the plasma}

The conversion of TCE in the plasma is shown in Fig. 11 as a function of the input energy density, for the discharge gap lengths of 1,3 and $5 \mathrm{~mm}$. The input energy is defined as the average power dissipated in the discharge divided by the total gas flow rate.

For the discharge gaps of 1 and $3 \mathrm{~mm}$ TCE conversion has similar values. It increases with input energy, reaching almost

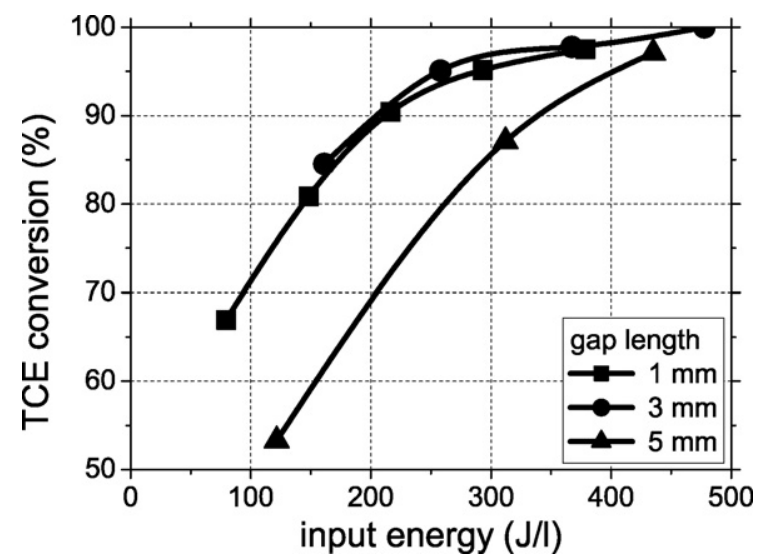

Fig. 11. TCE conversion in the plasma as a function of the input energy density, for the discharge gap lengths of 1,3 and $5 \mathrm{~mm}$.

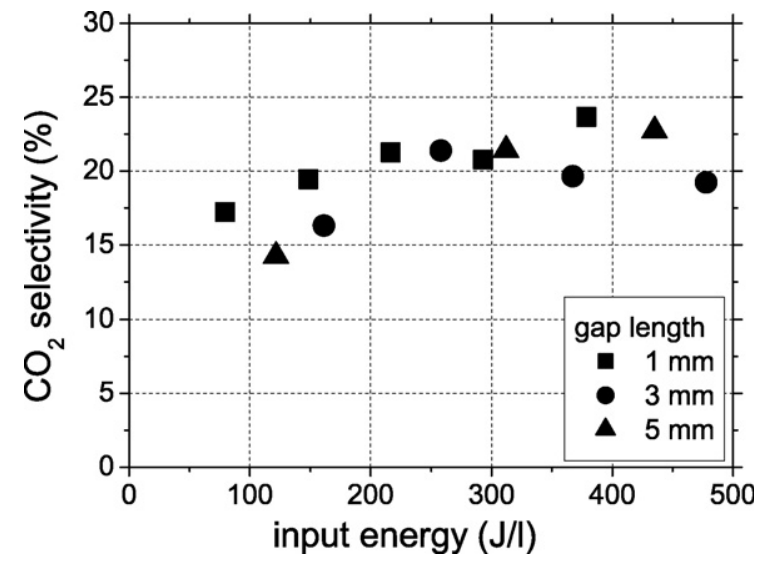

Fig. 12. Selectivity towards $\mathrm{CO}_{2}$ as a function of the input energy density, for the discharge gap lengths of 1,3 and $5 \mathrm{~mm}$.

$100 \%$ for energies above $400 \mathrm{~J} / \mathrm{l}$. For the $5 \mathrm{~mm}$ gap length TCE conversion is significantly lower for input energies in the range $100-300 \mathrm{~J} / 1$ and reaches approximately $95 \%$ only over $400 \mathrm{~J} / \mathrm{l}$. Therefore, shorter gap lengths appear to be more advantageous from the point of view of VOC decomposition.

The selectivity towards $\mathrm{CO}_{2}$ is plotted in Fig. 12 as a function of the input energy density, for the three gap lengths used. No significant effect of the gap length on the $\mathrm{CO}_{2}$ selectivity is observed over the energy range investigated. The selectivity is rather low, in the range $14-24 \%$. The values for the selectivity to $\mathrm{CO}$ are similar to those for $\mathrm{CO}_{2}$, ranging between $11 \%$ and $23 \%$. The selectivity to $\mathrm{CO}$ is also not influenced by the gap length.

There are two opposite effects of changing the gap length. When decreasing the length of the discharge gap the maximum electric field and the total charge transferred by the microdischarges increase. On the other hand, the residence time of the gas in the plasma region decreases when decreasing the gap length. It appears that the influence of the residence time on TCE oxidation is less pronounced, which may explain the behavior of TCE conversion shown in Fig. 11. The effect of residence time on TCE oxidation was investigated in Ref. [20] by varying the flow rate $(200-510 \mathrm{sccm})$ while keeping the

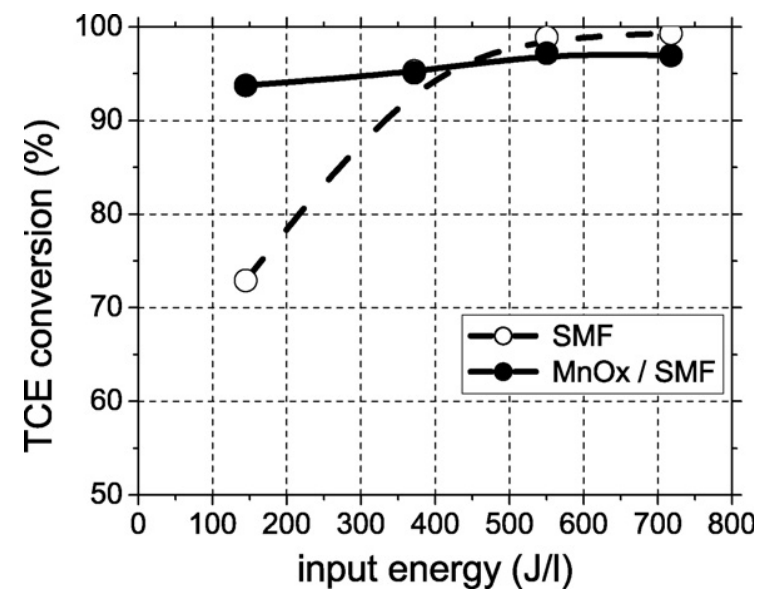

Fig. 13. TCE conversion as a function of input energy, for inner electrodes made of SMF and MnOx/SMF. 
same electrode configuration. It was found that the residence time did not influence TCE conversion over the range of input energies used (120-2330 J/1). The selectivity to $\mathrm{CO}_{2}$ was slightly higher for the higher residence time.

\subsection{TCE decomposition in the plasma-catalytic system}

In these experiments SMF and $\mathrm{MnOx} / \mathrm{SMF}$ were used as the inner electrode of the discharge reactor. The discharge gap was $2 \mathrm{~mm}$. The TCE conversion is shown in Fig. 13 and the selectivities to $\mathrm{CO}$ and $\mathrm{CO}_{2}$ are shown in Fig. 14.

For the SMF electrode TCE conversion increases from $73 \%$ to almost $100 \%$ with increasing the input energy in the range $150-720 \mathrm{~J} / \mathrm{l}$. With the MnOx/SMF electrode TCE conversion is significantly higher at low input energy, exceeding $90 \%$ at $150 \mathrm{~J} / \mathrm{l}$. The selectivity to $\mathrm{CO}$ is between $15 \%$ and $20 \%$ with the SMF electrode and decreases slightly with the MnOx/SMF. The selectivity to $\mathrm{CO}_{2}$ ranges between $15 \%$ and $25 \%$ with the SMF and shows a marked increase with the MnOx catalyst, to 25$60 \%$ over the range of input energies used.

The improvement in TCE conversion and $\mathrm{CO}_{2}$ selectivity in the presence of $\mathrm{MnOx}$ may be attributed mainly to its ability to decompose ozone forming strong oxidizing species. In a similar set-up [24] the ozone concentration detected in the effluent gas was $\sim 900 \mathrm{ppm}$ when using the SMF electrode under similar discharge conditions as in the present work $(15 \mathrm{kV}$ peak voltage and $195 \mathrm{~J} / 1$ input energy) and it decreased to $\sim 100 \mathrm{ppm}$ with the $\mathrm{MnOx} / \mathrm{SMF}$ electrode. The oxidizing species formed on the catalyst surface lead to enhanced TCE total oxidation.

\subsection{Reaction products of TCE decomposition}

Carbon dioxide and carbon monoxide were detected as reaction products of TCE decomposition in the plasma, accounting for $25-45 \%$ of the reacted carbon over the range of input energy used in these experiments. Some chlorinated by-products were detected as well by GC-MS, including mainly dichloroacetyl chloride $\left(\mathrm{CHCl}_{2}-\mathrm{CClO}, \mathrm{DCAC}\right)$, but also small amounts of trichloroacetyl chloride $\left(\mathrm{CCl}_{3}-\mathrm{CClO}\right.$,

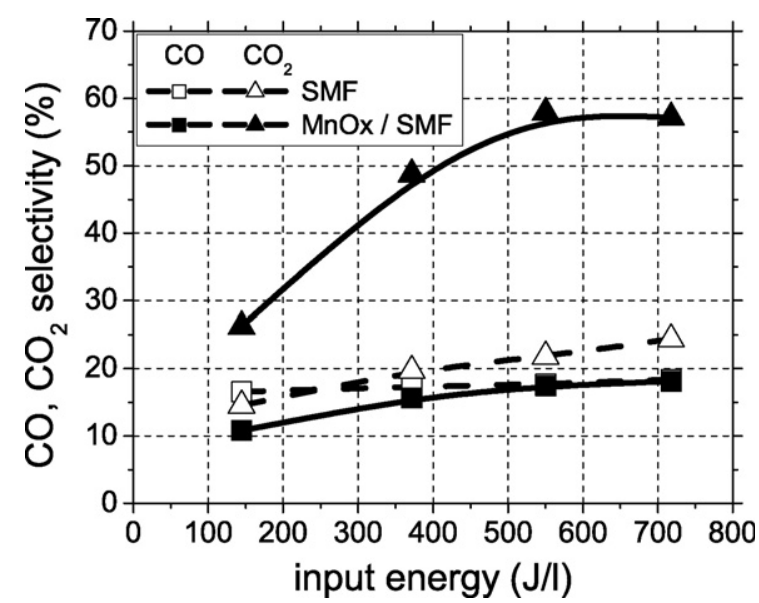

Fig. 14. Selectivity to $\mathrm{CO}$ and $\mathrm{CO}_{2}$ as a function of input energy, for inner electrodes made of SMF and MnOx/SMF.
TCAC) and trichloroacetaldehyde $\left(\mathrm{Cl}_{3} \mathrm{C}-\mathrm{CHO}\right.$, TCAA). Some higher hydrocarbons were also observed: octanal, nonanal, decanal, 1-chloro octane and 1-chloro nonane. Besides these products, the formation of $\mathrm{HCl}$ and $\mathrm{Cl}_{2}$ is expected; since the chlorinated reaction products represent less than $25 \%$ from the composition of the effluent gas, the major part of the introduced chlorine is most likely eliminated as $\mathrm{HCl}$ and $\mathrm{Cl}_{2}$. Small amounts of polymeric deposits are formed on the walls of the plasma reactor and on the inner electrode, accounting for about $5 \%$ of the reacted carbon. This figure was estimated by weighing the plasma reactor before and after the reaction, however the polymeric deposits were not analyzed in the present work. Very small amounts of $\mathrm{NO}$ and $\mathrm{NO}_{2}$ (below $10 \mathrm{ppm}$ each) were detected in the effluent gas under the present experimental conditions.

When the MnOx catalyst was introduced in the plasma the concentration of $\mathrm{CO}$ was not significantly changed, so it cannot justify the increase in the selectivity to $\mathrm{CO}_{2}$. However, other reaction products, like DCAC and TCAC disappear completely in the presence of $\mathrm{MnOx}$ and in addition the amount of higher hydrocarbons detected in the effluent gas is drastically reduced as well. This can explain, at least partially the increased $\mathrm{CO}_{2}$ selectivity.

Several investigations on TCE removal in DBD and corona discharges $[9,16]$ report also low selectivity to $\mathrm{CO}_{x}$. The major reaction products reported in these studies were DCAC and phosgene $\left(\mathrm{COCl}_{2}\right)$. Kirkpatrick et al. [6] detected DCAC as the primary byproduct of TCE decomposition as well. They suggested as possible pathway for the production of DCAC under dry conditions the reaction of TCE with $\mathrm{ClO}$ radicals:

$$
\mathrm{C}_{2} \mathrm{HCl}_{3}+\mathrm{ClO} \rightarrow \mathrm{CHCl}_{2} \mathrm{COCl}+\mathrm{Cl}
$$

Evans et al. [11] developed a kinetic model for plasma remediation of TCE using a DBD in $\mathrm{Ar} / \mathrm{O}_{2} / \mathrm{H}_{2} \mathrm{O}$ mixtures. The model predicts as major byproduct phosgene, formed by the reaction of $\mathrm{ClO}$ radicals with TCE, and also small amounts of formyl chloride $(\mathrm{CHOCl})$. Other byproducts of TCE oxidation in plasma detected by Futamura et al. [8] include pentachloroethane $\left(\mathrm{Cl}_{3} \mathrm{C}-\mathrm{CHCl}_{2}\right)$, dichloroacetonitrile $\left(\mathrm{Cl}_{2} \mathrm{CH}-\mathrm{CN}\right)$ and small amounts of tetrachloroethylene $\left(\mathrm{Cl}_{2} \mathrm{C}=\mathrm{CCl}_{2}\right)$, and chloroacetylene $(\mathrm{ClC} \equiv \mathrm{CH})$. However, we did not detect any of these products under the present experimental condition.

Futamura et al. [7] suggested the generation of unstable alkylperoxyl radicals, which further decompose oxidatively to form $\mathrm{CO}$ and $\mathrm{CO}_{2}$, as in the general reaction:

$$
\mathrm{R}^{\bullet}+\mathrm{O}_{2} \rightarrow \mathrm{ROO}^{\bullet} \rightarrow \text { intermediates } \rightarrow \mathrm{CO}+\mathrm{CO}_{2}
$$

They explained the very low amount of phosgene obtained in their experiments by scavenging carbon radicals by oxygen molecules and rapid oxidative decomposition of alkylperoxy radicals at low temperatures [7].

Regarding the reaction mechanism responsible for TCE removal in the plasma, decomposition by direct electron impact is unlikely, due to the low concentration of TCE in air. Urashima and Chang [1] suggested that TCE oxidation takes place by radicals or via oxidation of negative ions. Futamura and Yamamoto [7] suggest that TCE dissociation is initiated by 


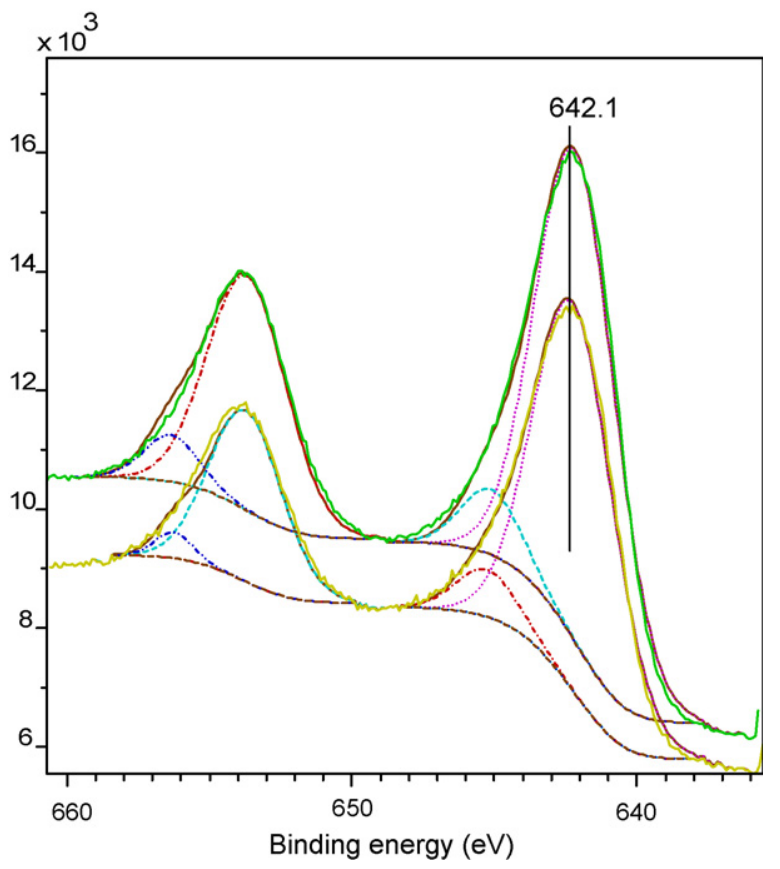

Fig. 15. XPS spectra of Mn 2p region for (a) fresh catalysts and (b) catalysts used for TCE removal in the dielectric barrier discharge.

elimination of chlorine or hydrogen atoms from excited TCE. Secondary decomposition of TCE can be induced by radicals formed from the initial decomposition, which explains the similar or even higher decomposition efficiency obtained for higher initial concentrations of TCE [7,20].

The interaction of ozone with manganese oxide catalysts is known to form reactive atomic oxygen species [12,22]. This can explain the improved results obtained when using the $\mathrm{MnOx} / \mathrm{SMF}$ as inner electrode. In the present reactor design, since the catalyst is located directly in the discharge region, reactions on the catalyst surface with chemically active species generated in the plasma enhance TCE decomposition as well.

\subsection{Catalysts characterization}

Both fresh catalysts and the catalysts used in the TCE oxidation in the dielectric barrier discharge were investigated by XPS. Fig. 15 shows the spectra recorded for the Mn $2 p$ level. A binding energy value $(\mathrm{BE})$ of $642.1 \pm 0.1 \mathrm{eV}$ with $\Delta E$ of $11.4 \pm 0.1 \mathrm{eV}$ was determined for both catalysts, indicating that the (IV) oxidation state of Mn was well preserved after the reaction. These BEs are in good agreement with those previously reported by Allen et al. for these species [28].

The Fe $2 \mathrm{p}_{3 / 2}$ peak with a binding energy at $711.4-711.6 \mathrm{eV}$ corresponds to an $\mathrm{Fe}(\mathrm{III})-\mathrm{O}$ environment, according to Thomas et al. [29]. Like for manganese, no change in the oxidation

Table 1

Binding energies (BE) and atomic ratios for the fresh and used catalysts

\begin{tabular}{lllll}
\hline Catalyst & Mn 2p & Fe 2p & O 1s & Fe/Mn ratio \\
\hline Fresh catalyst & 642.1 & 711.6 & 531.3 & 0.11 \\
Used catalyst & 642.2 & 711.4 & 531.5 & 0.27 \\
\hline
\end{tabular}

state of Fe was determined after exposing the catalyst to the plasma.

Table 1 summarizes the binding energies and atomic ratios for the fresh and used catalysts. Although both manganese and iron preserved after the reaction the oxidation state of the fresh catalysts, the atomic XPS Fe-to-Mn ratio indicates that a redispersion of manganese occurred during the reaction. The data presented in Table 1 indicates that iron enriches on the catalyst surface after the plasma test.

The XPS analysis revealed also some chlorine deposition on the catalyst surface.

\section{Conclusions}

The decomposition of trichloroethylene by non-thermal plasma generated in a dielectric barrier discharge was investigated. The influence of the discharge gap length on the electrical characteristics of the DBD and on the decomposition of TCE was studied. The increase of the average power dissipated in the discharge with voltage is steeper as the discharge gap increases. At constant applied voltage, the total charge transferred by the microdischarges is higher for short gap lengths.

Shorter gap lengths (1-3 mm) appear to be more advantageous with respect to TCE decomposition, even if the residence time of the treated gas in the plasma region is shorter. Similar values of TCE conversion were obtained for the gap lengths of 1 and $3 \mathrm{~mm}$, ranging between $67 \%$ and $100 \%$ for input energy densities in the range $80-480 \mathrm{~J} / \mathrm{l}$, while for the $5 \mathrm{~mm}$ discharge gap the conversion was lower, between $53 \%$ and $97 \%$, for similar values of the input energy. The selectivity to $\mathrm{CO}_{2}$ was in the range $14-24 \%$ and the selectivity to CO was $11-23 \%$ for the input energies mentioned previously, and was not influenced by the gap length. Other reaction products were detected, including dichloroacetyl chloride, trichloroacetyl chloride, trichloroacetaldehyde and several higher hydrocarbons, as octanal, nonanal, decanal, 1-chloro octane and 1-chloro nonane.

TCE conversion and $\mathrm{CO}_{2}$ selectivity were significantly enhanced using $\mathrm{MnOx} / \mathrm{SMF}$ catalysts as inner electrode of the discharge reactor, as compared to the case without catalysts. In the plasma-catalytic reactor TCE conversion reached $\sim 95 \%$ at the lowest input energy used $(144 \mathrm{~J} / \mathrm{l})$, and the selectivity to $\mathrm{CO}_{2}$ was close to $60 \%$ above $550 \mathrm{~J} / 1$. In this case the concentrations of the above-mentioned by-products decreased substantially. Chlorine was detected on the catalyst surface after the reaction by XPS.

XPS analysis of the fresh catalysts and the catalysts used in the plasma showed that both manganese and iron preserved after the reaction the oxidation state of the fresh catalysts, however the atomic Fe-to-Mn ratio suggests a redispersion of manganese on the catalysts surface during the reaction.

\section{Acknowledgements}

The authors acknowledge financial support from the Swiss National Science Foundation (SCOPES program). The work 
was partly financed also by the Romanian Ministry for Education and Research (CEEX program).

\section{References}

[1] K. Urashima, J.-S. Chang, IEEE Trans. Dielect. Elect. Insul. 7 (5) (2000) 602-614.

[2] U. Kogelschatz, Plasma Chem. Plasma Process. 23 (1) (2003) 1-46.

[3] S. Futamura, A.H. Zhang, T. Yamamoto, J. Electrostatics 42 (1997) 51-62.

[4] S. Futamura, A.H. Zhang, T. Yamamoto, IEEE Trans. Ind. Appl. 35 (4) (1999) 760-766.

[5] K.-P. Francke, H. Miessner, R. Rudolph, Plasma Chem. Plasma Process. 20 (3) (2000) 393-403.

[6] M.J. Kirkpatrick, W.C. Finney, B.R. Locke, Plasmas Polym. 8 (3) (2003) $165-177$.

[7] S. Futamura, T. Yamamoto, IEEE Trans. Ind. Appl. 33 (2) (1997) 447-453.

[8] S. Futamura, H. Einaga, A. Zhang, IEEE Trans. Ind. Appl. 37 (4) (2001) 978-985.

[9] M.C. Hsiao, B.T. Merritt, B.M. Penetrante, G.E. Vogtlin, P.H. Wallman, J. Appl. Phys. 78 (1995) 3451-3456.

[10] R. Vertriest, R. Morent, J. Dewulf, C. Leys, H. Van Langenhove, Plasma Sources Sci. Technol. 12 (2003) 412.

[11] D. Evans, L.A. Rosocha, G.K. Anderson, J.J. Coogan, M.J. Kushner, J. Appl. Phys. 74 (1993) 5378-5386.

[12] S. Futamura, A. Zhang, H. Einaga, H. Kabashima, Catal. Today 72 (2002) 259-265.

[13] T. Oda, T. Takahashi, K. Tada, IEEE Trans. Ind. Appl. 35 (2) (1999) 373-379.
[14] T. Oda, T. Takahashi, S. Kohzuma, IEEE Trans. Ind. Appl. 37 (4) (2001) 965-970.

[15] T. Oda, K. Yamaji, T. Takahashi, IEEE Trans. Ind. Appl. 40 (2) (2004) 430-436.

[16] S.B. Han, T. Oda, R. Ono, IEEE Trans. Ind. Appl. 41 (5) (2005) $1343-$ 1349.

[17] T. Oda, T. Takahashi, K. Yamaji, IEEE Trans. Ind. Appl. 40 (5) (2004) $1249-1256$

[18] T. Oda, J. Electrostatics 57 (2003) 293-311.

[19] M. Magureanu, N.B. Mandache, E.M. Gaigneaux, C. Paun, V.I. Parvulescu, J. Appl. Phys. 99 (2006).

[20] M. Magureanu, N.B. Mandache, V.I. Parvulescu, Plasma Chem. Plasma Process., in press.

[21] M. Magureanu, N.B. Mandache, P. Elloy, E.M. Gaigneaux, V.I. Parvulescu, Appl. Catal. B: Environ. 61 (2005) 12-20.

[22] Ch. Subrahmanyam, M. Magureanu, A. Renken, L. Kiwi-Minsker, Appl. Catal. B: Environ. 65 (2006) 150-156.

[23] Ch. Subrahmanyam, A. Renken, L. Kiwi-Minsker, Appl. Catal. B: Environ. 65 (2006) 157.

[24] Ch. Subrahmanyam, A. Renken, L. Kiwi-Minsker, Plasma Chem. Plasma Process. 27 (2007) 13.

[25] Ch. Subrahmanyam, A. Renken, L. Kiwi-Minsker, Chem. Eng. J., in press.

[26] M. Krauss, B. Eliasson, U. Kogelschatz, A. Wokaun, Phys. Chem. Chem. Phys. 3 (2001) 294.

[27] Z. Falkenstein, J.J. Coogan, J. Phys. D: Appl. Phys. 30 (1997) 817-825.

[28] G.C. Allen, S.J. Harris, J.A. Jutson, J.M. Dyke, Appl. Surf. Sci. 37 (1989) 111.

[29] J.E. Thomas, C.F. Jones, W.M. Skinner, R.St.C. Smart, Geochim. Cosmochim. Acta 62 (1998) 1555. 